\title{
Testing The Convergence Hypothesis Using Time Series Techniques: The Case Of Greece 1971-1996
}

\author{
D. Asteriou, (d.asteriou@city.ac.uk) City University, London \\ S. Karagianni, (stelkar@uom.gr) University of Macedonia \\ C. Siriopoulos, (siriopoulos@edekt-ote.gr) University of Macedonia
}

\begin{abstract}
Over the last five years, few issues have proven more controversial in empirical economics than the so-called convergence hypothesis. This paper considers the issue of convergence across Greek regions, using time series techniques. Our empirical results support the popular view prevailing in Greece about the existence of dualism across the Southern and Northern regions of Greece. A possible explanation for this may be the lack of experience that the poor countries (like Greece) have in comparison with the rich ones. The rich countries have the combined ability to educate themselves as they grow rich and the endogenous ability to accumulate the knowledge upon which these efforts are made. Also, the same argument can be used as an explanation for the regional differences -the fact that the poor regions do not have previous experience and knowledge for efficient investments.
\end{abstract}

\section{Introduction}

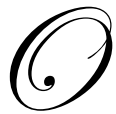

ver the last five years, few issues have proven more controversial in empirical economics than the socalled convergence hypothesis. In the bulk of this literature, convergence has been defined as a negative correlation -after controlling for some set of variables- between initial income and growth for a crosssection of countries, regions, states, or even more families. Much of the interest in this correlation stems from its purported implications for the shape of the aggregate production function and hence the empirical relevance of endogenous growth theory.

The neoclassical growth models for closed economies, as presented by Solow (1956), suggest that the per capita growth rates tends to be inversely related to the starting level of output or income per person. In particular, if economies are similar in respect to preferences and technology, then poor economies grow faster than rich ones, promoting convergence in levels of per capita product and income. Thus, the main conclusion of those models is that poor countries or regions, should tend to catch up to rich ones through time, implying convergence.

Baumol (1986) examines convergence from 1870 to 1979 among the 16 industrialized countries. He argues that convergence has shown itself strongly in the growth of industrial nations since 1870 . He bases this conclusion on a regression of growth from 1870 since 1979 on the initial productivity level. However De Long (1988) demonstrates that Baumol's (1986) findings, is largely spurious. He finds two problems. The first is sample selection. Since historical data are constructed retrospectively, the countries that have long data series are those that are more industrialized today. Thus countries that were not rich a hundred years ago are typically in the sample only if they grew rapidly over the next hundred years. In contrast, countries that were rich a hundred years ago, are generally included even if their subsequent growth was only moderate. The second problem is measurement error. Estimates of real income per capita in 1870 are imprecise, and this measurement error creates bias toward finding convergence. De Long (1988) analysis suggests that there are no forces pushing for convergence. In the same line of argumentation, Romer (1986) and Rebelo (1991) suggest that the absence of convergence across economies

Readers with comments or questions are encouraged to contact the authors via email.

throughout the world represented strong evidence against the neoclassical model and in favor of their theories of 
endogenous growth.

Recent papers by Dowrick and Nguyen (1989), Barro and Sala-i-Martin (1991, 1992), Mankiw, Romer and Weil (1992) and Lightenberg (1992), among others, have investigated the sources of growth and convergence, using explicitly formulated growth models as a framework for empirical analysis. Barro and Sala-i-Martin (1991, 1992) employee an equation, which is in accordance with the neoclassical framework of analysis, in order to test empirically the existence or not of convergence. The overall evidence of their analysis weighs heavily in favor of convergence, suggesting that the results of the neoclassical growth models are valid. Examining the growth and dispersion of personal income in United States (U.S.) states and regions, as well as in 73 regions of seven European countries, they conclude that poor states and/or regions really tend to grow faster in terms of per capita income and product, with a rate of convergence, approximately $2 \%$ per year, for both U.S. states and European regions (Barro and Sala-i-Martin, 1991). Also, in their 1994 study they extended the empirical evidence on regional growth and convergence across the U.S., Japan and European nations, confirming that the estimated speeds of convergence are surprisingly similar across data sets and that all regions tend to converge again at the same speed (of approximately $2 \%$ per year). Mankiw, Romer and Well (1992), examine the implications of the Solow (1956) model for convergence in standards of living and their evidence indicates that, holding population growth and capital accumulation constant, countries converge about the rate the augmented Solow model predicts. Finally, other recent studies upon the subject of convergence support the theory of the neoclassical model. Specifically, Coulombe and Lee (1995) find convergence across Canadian provinces from 1961 to 1991, and Cashin (1995), suggests that there exists convergence across the seven colonies of Australia.

Although the neoclassical economic theory predicts convergence, the empirical evidence has been a subject for debate. Indeed the findings of Barro and Sal-i-Martin $(1991,1992)$ have been subject to criticism and thorough examination from other analysts. Specifically, Mauro and Podrecca (1994) examined empirically the convergence hypothesis for the case of Italian regions, using the Barro and Sala-i-Martin framework of analysis. Their findings were the opposite of those that Barro and Sala-i-Martin (1991) for the same case -convergence across Italian regions- suggested the rejection of the convergence hypothesis in all cases, and the existence of economic dualism between Northern and Southern Italy. Pagano (1993) studying productivity or income convergence in the European Community countries suggests that the process of convergence stops or even reverse with the oil shocks of 1970's. Neven and Gouyete (1994) suggest that there exist dualism between Southern and Northeastern Regions of European Community, and Button and Pentecost (1995) testing the convergence in the European Union regional economies finds no significant convergence across those regions in the 1980's. Siriopoulos and Asteriou (1998) also, found no evidence for convergence across the Greek regions or across the Greek prefectures.

In addition, Cheshire and Carbonaro (1995 and 1997) suggested that measured $B$-convergence neither constitutes a useful test of the neoclassical growth theory nor does it provide a robust measure of convergence/divergence. They proved this both in principle and in measurement terms. (See also Mavroudeas and Siriopoulos 1998 for a critic of the neoclassical model). In the same line of argumentation the critique made by Quah (1993, 1996a and 1996b) concludes that the most theoretical and mainly empirical investigations of the convergence hypothesis were incapable of answering correctly the question whether the rich economies will converge with the poor ones. Their main criticism was based on the problems of the cross-sectional data. The crosssectional analysis, suffer from several problems. It is possible for a set of economies, which are diverging to exhibit the sort of negative correlation described by the neoclassical theory, so long as the marginal product of capital is diminishing. Also, the cross-section procedures work with the null hypothesis that no countries are converging and the alternative that all countries are not, which leave out a host of intermediate cases.

In this line, Bernand and Durlauf (1995), proposed a new methodology, using time series techniques, rather than cross-section methods, to test for the convergence hypothesis. In their analysis, they apply empirical tests for convergence among 15 OECD economies, and their results suggest the rejection of the convergence hypothesis.

In this paper, we examine income convergence across the regions of Greece. The issue of catching up or lagging behind, is critical for the case of Greece, not only from the point of view of the Greek economy, but also from the point of view of the European unification project. The European Economy will be able to reap the benefits of cooperation and specialization only to the extend in which the individual economies benefit from the integration 
process. We test for convergence using the new methodology (Bernand and Durlauf 1995), employing time series techniques. Our empirical results support the hypothesis of the existence of dualism across the Southern and Northern regions of Greece. Our findings cast also doubt on the neoclassical model of growth, while our results suggest that conditional beta convergence regressions do not hold for the Greek case. In the next section, we present the theoretical framework and the methodology our analysis follows, and in the third section we give the empirical results. Finally we conclude with thoughts about the economic position of Greek regions.

\section{Methodology}

Following the definitions of Bernard and Durlauf (1995), we define convergence for a group of countries to mean that each region has identical long-run trends, either stochastic or deterministic, while common trends allow for proportionality of the stochastic elements. These definitions lead naturally to the use of cointegration techniques in testing the convergence hypothesis. If long-run technological progress contains a stochastic trend, or unit root, then convergence implies that the permanent components in output are the same across regions. The theory of cointegration provides a natural setting for testing cross-regional relationships in permanent output movements.

First, we define as $y_{t}^{i}=\log \left(Y_{t}^{i} / Y_{t}\right)$ where $Y_{t}^{i}$ represents the per capita income of each region, and $Y_{t}$ represents the aggregate per capita income over all units (in our case the per capita income of Greece) at each $t$. The superscript $\mathrm{i}$ indicates each region. Regions $i$ and $j$ converge if the long term forecasts of output for both countries are equal at a fixed time t. This means that the two regions are cointegrated with cointegrating vector [1, -1$]$. Alternatively, we can define as absence of convergence the situation where the differences $\left(y_{t}^{i}-y_{t}^{j}\right)$ contain unit roots. The above definition of convergence can be used also in order to test whether the two regions have a common trend in their output series. Regions $i$ and $j$ have a common trend if their output series are cointegrated with cointegrated vector $[1,-\mathrm{a}]$.

In order to test for convergence and common trends, we employ multivariate techniques developed by Johansen (1988). The starting point for the empirical work is the finding that the output vectors of each region $\left(Y_{t}^{i}\right)$ are integrated of order one. Then we assume that a finite-vector autoregressive representation exist and we can rewrite the output vector processes as:

$$
\begin{aligned}
& \Delta y_{t}^{i}=\Gamma_{1} \Delta y_{t-1}^{i}+\cdots+\Gamma_{k-1} \Delta y_{t-k-1}^{i}+\Pi y_{t-k}^{i}+\psi D_{t}+\varepsilon_{t} \\
& \varepsilon_{\mathrm{t}} \sim \operatorname{IN}(0, \Sigma)
\end{aligned}
$$

where the estimates of $\Gamma_{1}=-\left(I-A_{1}-\cdots-A_{i}\right),(1, \cdots k-1)$ describe the short-run dynamics to changes in $y_{t}^{i}$, $\Pi=-\left(I-A_{1}-\cdots-A_{i}\right)$ captures the long run adjustments, the A matrices are the autoregressive parameter matrices from the unrestricted VAR, and $D$ contains deterministic terms.

Additionally, if the data cointegrate $\Pi$ must be of reduced rank $r<p$, where $p$ is the number of variables entering the vector $y$ and $r$ is the number of cointegrating relationships. In this case, $\Pi$ can be factored as $\Pi=\alpha \beta^{\prime}$, where $\beta$ and $\alpha$ are $p \times r$ matrices, which give the cointegrating vectors and associated adjustment matrix, respectively.

If the rank of $\Pi$ equals $p$, then each $Y_{t}^{i}$ is a stationary process. If the rank of $\Pi$ is $0<r<p$, there are $r$ cointegrating vectors for the individual series in $Y_{t}^{i}$ and hence the group of time series is being driven by $p-r$ common shocks. If the rank of $\Pi$ equals zero, there are $p$ stochastic trends and the long-run output levels are not related across regions.

In particular, in order to have regional convergence there must be $p-1$ cointegrating vectors of the form $(1,-$ 1) or one common long-run trend. Two test statistics proposed by Johansen to test the rank of the cointegrating matrix are derived from the eigenvalues of the MLE estimate of $\Pi$, the trace statistic (which tests the null hypothesis 
that the rank of the cointegrating matrix is $r$ against the alternative that the rank is $p$ ) and the maximum eigenvalue statistic (which tests the null hypothesis that the rank $r$ against the alternative that the rank is $r+1$ ).

In our empirical analysis we apply both tests in order to test the convergence hypothesis and the presence or not of common trends, using time series data (of per capita output in constant prices) for the Greek regions and especially for the period from 1971 to 1996.

\section{Empirical Results}

The results of the first direct test for the convergence hypothesis are presented in table 1 . The evidence on convergence is quite striking. It is clear that all the series contain unit roots, which indicates the absence of convergence. This finding is in favour of the popular view prevailing in Greece about the persistence of inequality that exists amongst the Northern and the Southern part of the country.

Table 1

Tests Of the Convergence Hypothesis

$$
\begin{aligned}
& \text { Unit Root test of the variable } \\
& \mathrm{X} 1=\mathrm{In}\left(\mathrm{Y}^{\text {SOUTHERN GR }} / \mathrm{Y}^{\mathrm{GR} . \text { TOTAL }}\right)-\operatorname{In}\left(\mathrm{Y}^{\text {NORTHERN GR. }} / \mathrm{Y}^{\text {GR.TOTAL }}\right) \\
& \text { Unit Root test of the variable }
\end{aligned}
$$

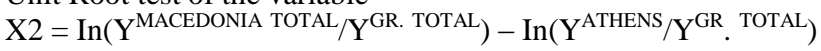

$$
\begin{aligned}
& \text { * 95\% Critical Values in parentheses }
\end{aligned}
$$

Having failed to find evidence for convergence, we turn to the test for the number of common trends. In order to test for common trends, we first test for the presence of stochastic trends in each of our 13 output series. Table 2 presents the results for Augmented Dickey-Fuller tests. None of the 13 regions reject the null hypothesis of a unit root. Then we test for cointegration applying the Johansen technique in three separate groupings of regions: a group of 10 regions (5 Southern and 5 Northern regions) a group, which contains only the southern regions and a group for the northern regions only.

Table 2

Unit Root tests

\begin{tabular}{lcccc}
\hline Regions & \multicolumn{2}{c}{ Log real per capita } & First differences of per output capita output \\
\hline Eastern Macedonia andThrace & $-0,2578$ & $(-2.9850)$ & $-3,1807$ & $(-2,9907)$ \\
Central Macedonia & $-1,789$ & $(-2.9850)$ & 4,0374 & $(-2,9907)$ \\
Western Macedonia & $-1,0947$ & $(-2.9850)$ & $-4,0190$ & $(-2,9907)$ \\
Hipiros & $-1,9643$ & $(-2.9850)$ & $-4,7938$ & $(-2,9907)$ \\
Thessalia & $-1,4738$ & $(-2.9850)$ & $-4,1656$ & $(-2,9907)$ \\
Peloponisos & $-1,4134$ & $(-2.9850)$ & $-4,0737$ & $(-2,9907)$ \\
Western Greece & $-2,0582$ & $(-2.9850)$ & $-3,8067$ & $(-2,9907)$ \\
Sterea & $-1,8889$ & $(-2.9850)$ & $-4,1509$ & $(-2,9907)$ \\
Athens & $-2,1034$ & $(-2.9850)$ & $-3,2714$ & $(-2,9907)$ \\
Crete & $-1,2734$ & $(-2.9850)$ & $-7,4929$ & $(-2,9907)$ \\
\hline
\end{tabular}

* 95\% Critical Values in parentheses

Describing the procedure of the test, we can say that in the fist column we present the results of the test for existence or not, of unit root in the log levels of our variables. The statistical values are smaller than the critical for all cases and so we cannot reject the null hypothesis of existence of unit root. Similarly, in the second column, we present the results of the same test but this time in the first differences of our variables. This time, the statistical values are greater than the critical values rejecting the null hypothesis of unit root in the first differences. Therefore, all our variables are integrated of order one 1(1).

The multivariate results from the Johansen trace and maximum eigenvalue statistics on convergence and cointegration are presented in Table 3, for a lag length of 1 . The lag length was chosen using the BIC criterion. The two statistics in the first case give different estimates of the cointegrating vectors. The Johansen trace statistic rejects 4 or fewer cointegrating vectors at the 5\% level for the entire ten-region sample. This implies that there are 6 or 7 shocking forces for this group. The maximum eigenvalue statistic rejects for 6 or fewer cointegrating vectors, which 
suggests that there are 4 or 5 shocking forces. Taking the five Southern and the five Northern regions separately, the two statistics give the same results. For the five Southern regions both statistics reject for 2 or more trends at the 5\%, while for the five Northern regions the results reject the null that there are 5 distinct trends and cannot reject the null that there is at least 1 trend, again with both statistics. These results suggest that there are only 1 or 2 long-run processes driving output in the Greek regions.

Table 3

Multivariate tests for cointegration (VAR lag length = 1)

\begin{tabular}{ccccccccc}
\hline & All Regions & \multicolumn{3}{c}{ Southern Regions } & \multicolumn{2}{c}{ Northern Regions } \\
\hline Trends & Trace & Max & Trends & Trace & Max & Trends & Trace & Max \\
\hline$>9$ & 425,9 & 114,1 & $>4$ & 95,3 & 36,4 & $>4$ & $* 99,4$ & $* 46,9$ \\
$>8$ & 311,7 & 76,0 & $>3$ & $* 58,9$ & $* 28,8$ & $>3$ & 52,5 & 27,5 \\
$>7$ & 235,7 & 67,2 & $>2$ & 30,0 & 14,1 & $>2$ & 25,0 & 15,3 \\
$>6$ & 168,5 & $* 50,6$ & $>1$ & 15,9 & 12,2 & $>1$ & 9,7 & 5,8 \\
$>5$ & 117,8 & 39,6 & $>0$ & 3,6 & 3,6 & $>0$ & & \\
$>4$ & $* 78,1$ & 27,0 & & & & & & \\
$>3$ & 51,1 & 20,8 & & & & & & \\
$>2$ & 30,3 & 15,2 & & & & & & \\
$>1$ & 15,0 & 11,5 & & & & & & \\
$>0$ & 3,5 & 3,5 & & & & & &
\end{tabular}

\section{Concluding Remarks}

The present paper examines the issue of convergence across Greek regions, using time series techniques. Our empirical results are not in accordance with the neoclassical model and give evidence to the popular view prevailing in Greece, about the existence of economic dualism across the Southern and Northern regions of the country. These findings confirm previous empirical results (Siriopoulos and Asteriou 1998). A possible explanation for this may be the lack of experience that the poor countries (like Greece) have in comparison with the rich ones. The rich countries have the combined ability to educate themselves as they grow rich and the endogenous ability to accumulate the knowledge upon which these efforts are made. Also, the same argument can be used as an explanation for the regional differences -the fact that the poor regions do not have previous experience and knowledge for efficient investments.

In the issue of investments, it is true that the technological performance gap between Greece and its European counterparts appears to have become wider by the end of the 1990 's, contrary to the trend of the previous two decades. If one examines the level as well as the composition of investment in Greece during the 1980's it becomes clear that investment as a percentage of GDP declined by 6,8 percentage points (when the European average has been less than $1 \%$ ). If one takes investment for rationalization as a proxy of modernization and application of new techniques in the production process, again it becomes clear that Greece lags behind if compared with Europe as a whole.

Taking into account the diverging process that characterizes the Greek regions the conclusions that can be drawn is that, in order for regional (and national) policies to play the role of the catalyst of the viable development, in the new framework of challenges and opportunities, that the European integration process provides, they have to rearrange priorities and objectives. The regional development projects, pursued in the past, in the context of EU policies failed to alter the unplanned character of the Greek society, because they were themselves introduced simply as lists of public works rather than as programs. This previous experience must be used from the Greek policy makers in order not to face again the same problems.

Given the fact that the quantity of funds from EU is large enough the divergence path that the Greek economy follows can be explained, in terms of the allocated funding in various projects of questionable importance from a development point of view. Unless a shift away from quantitative and in favor of qualitative priorities takes place, it is highly likely that the absorption of EU funds will never lead Greek regions to convergence, or even more it will further reinforce the divergence dynamics of the Greek economy.

The existence of regional divergence across Greece, has important economic implications for the European 
Union. The convergence of economic regions is an important factor influencing the sustainability of a monetary union once it has been formed.

\section{Suggestions for Future Research}

Also, if we consider the fact, that we have strong evidence of existence of regional divergence for other EU members -such as, Greece, as showed in the present paper, Italy, (Mauro and Podrecca, 1994), or United Kingdom, (Chatterji and Dewhurst, 1996)- as Europe moves closer towards a full economic monetary union, the whole issue of convergence becomes more complicated, and leaves the agenda open for further research.

\section{References}

1. $\quad$ Barro R.J. and X. Sala-i-Martin (1991): "Convergence Across States and Regions", Brookings Papers on Economic Activity no. 1, pp. 107-182.

2. $\quad$ Barro R.J. and X. Sala-i-Martin (1992):"Convergence" Journal of Political Economy, Vol.100, No2, pp.223-251.

3. Baumol W. (1986): "Productivity, Growth, Convergence and Welfare: What the Long-Run Data Show", American Economic Review, 76, 5, pp. 1872-1085.

4. Bernard A. and S. Durlauf (1995): "Convergence in International Output", Journal of Applied Econometrics, Vol. 10, pp. $97-108$.

5. Button K. and E. Pentecost (1995): "Testing for Convergence of the EU Regional Economies", Economic Inquiry, 33, (4), pp. 664-671.

6. Cashin P. (1995): "Economic Growth and Convergence Across the Seven Colonies of Australia: 1861-1991", Economic Record, 71, (213), pp. 132-144.

7. Chatterji M. and J. H. Dewhurst (1996): "Convergence Clubs and Relative Economic Performance in Great Britain: 1977-1991", Regional Studies, Vol. 30,1, pp. 31-40.

8. Cheshire P. and G. Carbonaro (1995), "Convergence-Divergence in Regional Growth Rates: an empty black box?", in Armstrong and Vickerman (eds) Convergence and Disconvergence Among European Regions, Pion, London.

9. Cheshire P. and G. Carbonaro (1997), "Testing models, describing reality, or neither? ", in K.Peschel (ed) Regional Growth and Regional Policy within the Framework of European Integration, Physica-Verlag.

10. Coulombe S. and F. Lee (1995): "Convergence Across Canadian Provinces, 1961 to 1991", Canadian Journal of Economics, 28 (4a), pp. 886-898.

11. De Long B. (1988): "Productivity, Growth, Convergence and Welfare: Comment" American Economic Review, Vol. 78, n. 5, pp. 1138-1154.

12. Dowrick S. and D. T. Nguyen (1989): "OECD Comparative Economic Growth 1950-85: Catch-Up and Convergence", American Economic Review, Vol. 79, n. 5, pp. 1010-1030.

13. Johansen S. (1988): "Statistical Analysis of cointegration vectors", Journal of Economic Dynamics and Control, 12, pp. 231-254.

14. Lightenberg F. (1992): "R\&D Investment and International Productivity Differences", NBER Working Paper No. 4161.

15. Mankiw N.G., D. Romer and D.N. Well (1992): "A Contribution to the Empirics of Economic Growth", Quarterly Journal of Economics, 107, pp. 407-437.

16. Mauro L. and Podrecca E. (1994): "The Case of Italian Regions: Convergence or Dualism?", Economic Notes, 23 (3), pp. 447-472.

17. Mavroudeas S., and Siriopoulos C. (1998): "Convergence or Divergence: the case of Greece - Is the Data or the Model that do not compute?", The Journal of Applied Business Research, 14(1), pp. 149-157.

18. Neven D. and Gouyette C. (1994): "Regional Convergence in the European Community", Cahiers de Recherches Economiques, No. 9311, Working Paper, Universite de Lausanne.

19. Pagano P. (1993): "On Productivity Convergence in the European Community Countries: 1950-1988", Giornali degli Economisti e Annali di Economia, 52 (7-9), pp. 389-401.

20. Quah D. (1993): "Gallon's Fallacy and Tests on the Convergence Hypothesis", Scandinavian Journal of Economics, Vol. 95, pp.427-443.

21. Quah D. (1996a): "Empirics for Economic Gowth and Convergence", European Economic Review.

22. Quah D. (1996b): "Twin Peaks: growth and convergence in models of distribution dynamics", Economic Journal, vol 106, no. 437, pp. 1045-1055.

23. Rebelo S. (1991): "Long-Run Policy Analysis and Long-Run Growth", Journal of Political Economy, 99, pp. 500-521.

24. Romer P. (1986): "Increasing Returns and Long-Run Growth", Journal of Political Economy, 94, pp. 1002-1037.

25. Siriopoulos C. and Asteriou D. (1998): "Testing for convergence across the Greek Regions", Regional Studies, 32(6), pp. 537-546.

26. Solow R. (1956): "A Contribution to the Theory of Economic Growth", Quarterly Journal of Economics, 70, pp. 65-94. 